Article

\title{
Solution Extrusion Additive Manufacturing of Biodegradable Polycaprolactone
}

\author{
Jian-Ming Chen ${ }^{1,2} \oplus$, Demei Lee ${ }^{1}$, Jheng-Wei Yang ${ }^{1}$, Sheng-Han Lin ${ }^{1}$, Yu-Ting Lin ${ }^{1}$ \\ and Shih-Jung Liu 1,2,*(D) \\ 1 Department of Mechanical Engineering, Chang Gung University, Taoyuan 33302, Taiwan; \\ vantchen@gmail.com (J.-M.C.); dmlee@mail.cgu.edu.tw (D.L.); q26419391@yahoo.com.tw (J.-W.Y.); \\ em9455123@gmail.com (S.-H.L.); yutinna1201@gmail.com (Y.-T.L.) \\ 2 Department of Orthopedic Surgery, Chang Gung Memorial Hospital-Linkou, Taoyuan 33305, Taiwan \\ * Correspondence: shihjung@mail.cgu.edu.tw; Tel.: +886-3-2118166; Fax: +886-3-2118558
}

Received: 10 April 2020; Accepted: 1 May 2020; Published: 3 May 2020

\begin{abstract}
Polycaprolactone (PCL) is a resorbable semicrystalline polymer that degrades slowly via hydrolysis and has applications in medical implants and drug delivery. As a result of its low melting point, PCL can be processed easily by conventional polymer processing techniques. However, the additive manufacturing of PCL remains a challenge, mainly due to the fact that there are no commercially available filaments for traditional fused deposition modeling (FDM). Furthermore, when the materials are fabricated via FDM for drug delivery applications, the high temperature may deactivate the incorporated drugs/biomolecules. This study investigates the solution extrusion additive manufacturing of PCL using a lab-developed solution-type device. The device comprises a solution extrusion feeder, driving stepper motors, a power source, a syringe equipped with a dispensing tip, an accumulation platform, and a control interface. The influences of different manufacturing parameters on part quality were evaluated. The experimental results suggest that the tensile strength of the additively manufactured parts increases with fill density but decreases with the ratio of PCL to dichloromethane (DCM) and moving speed of the dispensing tip. Parts fabricated by $90^{\circ}$ print orientation of infill exhibited the greatest mechanical strength. The fabricated parts tend to heal the gaps among strips after additive manufacturing, but tiny pores can still be seen on the surfaces.
\end{abstract}

Keywords: polycaprolactone; additive manufacturing; solution extrusion; manufacturing parameter

\section{Introduction}

Polycaprolactone (PCL) is a biodegradable semicrystalline poly( $\alpha$-hydroxyester) that resorbs slowly by hydrolysis due to its high crystallinity and hydrophobic nature $[1,2]$. It is synthesized by ring-opening polymerization of $\varepsilon$-caprolactone. The material is semi-crystalline, its melting temperature is $59-64{ }^{\circ} \mathrm{C}$, and its glass transition temperature is $-60{ }^{\circ} \mathrm{C}$. PCL is extremely hydrophobic, so it has longer degradation periods than polylactide, making it appropriate for applications requiring long degradation times. In the human body, PCL is resorbed via hydrolysis of the ester linkages. Thus, it has gained much attention as a material for implantable devices. The polymer has also found applications in many fields, such as implantable biomaterials, biodegradable scaffolds, and micro-/nano-particles for drug delivery [3]. Various pharmaceuticals have been incorporated into PCL for drug delivery and targeted release. PCL scaffolds have also been developed for tissue engineering of bone and cartilage.

Additive manufacturing [4,5], which is also called 3D printing, is an easy and adaptable method for the fabrication of products of intricate geometry. The advantages of additive manufacturing include manufacturing options, short time to market, customization, and intricacy, making the process one 
of the most favored techniques. Through continuous deposition of filaments and layers, additive manufacturing provides a brand new method for product fabrication. The most commonly employed additive manufacturing method is called fused deposition modeling (FDM) [6]. The process expels thermoplastic melts from a nozzle and lays them onto the developing product. The extrusion nozzle moves in the $\mathrm{x}$ and $\mathrm{y}$ directions to compose one material layer each time. The nozzle then shifts in the $\mathrm{z}$ direction in tiny consecutive steps to make a fresh layer. The moving of the extruding nozzle is controlled by a microprocessor to eventually form a three-dimensional product.

The additive manufacturing of pure PCL or filled PCL composites, however, remains as a challenge, mainly due to the restricted availability of PCL filaments for FDM manufacturing [7,8]. To overcome this limitation, various works have been done. Guerra and Ciurana [9] developed a fused filament fabrication (FFF)-based printer for additive manufacturing of polycaprolactone stents. Jhao et al. [10] investigated the morphology and mechanical properties of hydroxyapatite/PCL scaffolds fabricated by a self-developed melt differential FDM 3D printer. Hollander et al. [11] employed FDM printing of PCL implants for the delivery of micronized indomethacin. Visscher et al. [12] combined FDM with a salt leaching method to develop a 3D printed PCL scaffold with dual micro- and macro-porosity. Despite these efforts, all these works were based on the FDM method, which employs high-temperature extrusions during the manufacturing process. Such a polymer extrusion process poses some restrictions, particularly when the fabricated product is employed as a device for drug delivery. Compounding polymers with pharmaceuticals at high temperatures in the melt extrusion of an additive manufacturing process can destroy or deteriorate the drugs [13].

This study proposed a novel method for additive manufacturing of PCL products using a solution extrusion layer-by-layer scheme. PCL materials and solvent were first mixed and expelled from a feeder equipped with a syringe and a dispensing tip (nozzle). The dispensing tip was controlled and moved by a computer and microprocessor. As soon as the solvent volatilized, the solution was driven from the dispensing tip, solidified, and was piled in continuous layers to make parts of desired geometries. A single factor experimental design was carried out to evaluate the influence of different processing parameters on the tensile properties of additive manufactured parts. After manufacturing, the strength of manufactured PCL specimens was determined by a tensile testing machine, and the morphology was evaluated by a projector microscope and a field emission scanning electron microscope (SEM). A differential scanning calorimeter (DSC) analysis was also done to investigate the thermal patterns of fabricated PCL parts.

\section{Materials and Methods}

\subsection{Materials}

The materials included PCL (molecular weight $\mathrm{M}_{\mathrm{n}}: 80,000 \mathrm{Da}$ ) and dichloromethane (DCM). Both were purchased from Sigma-Aldrich (St. Louis, Mo, USA).

\subsection{Empirical Setup}

The solution extrusion additive manufacturing was done on a lab-developed fabrication device (Figure 1). The device comprises a solution extrusion feeder, driving stepper motors and related components, a power source, a syringe, a dispensing tip with an inner diameter of $0.18 \mathrm{~mm}$ at the outlet (Figure 2), an accumulation platform, and a user interface with connectivity. An open Cura interface (Ultimaker B.V., Geldermalsen, The Netherlands) was employed to manage the whole manufacturing procedure. 


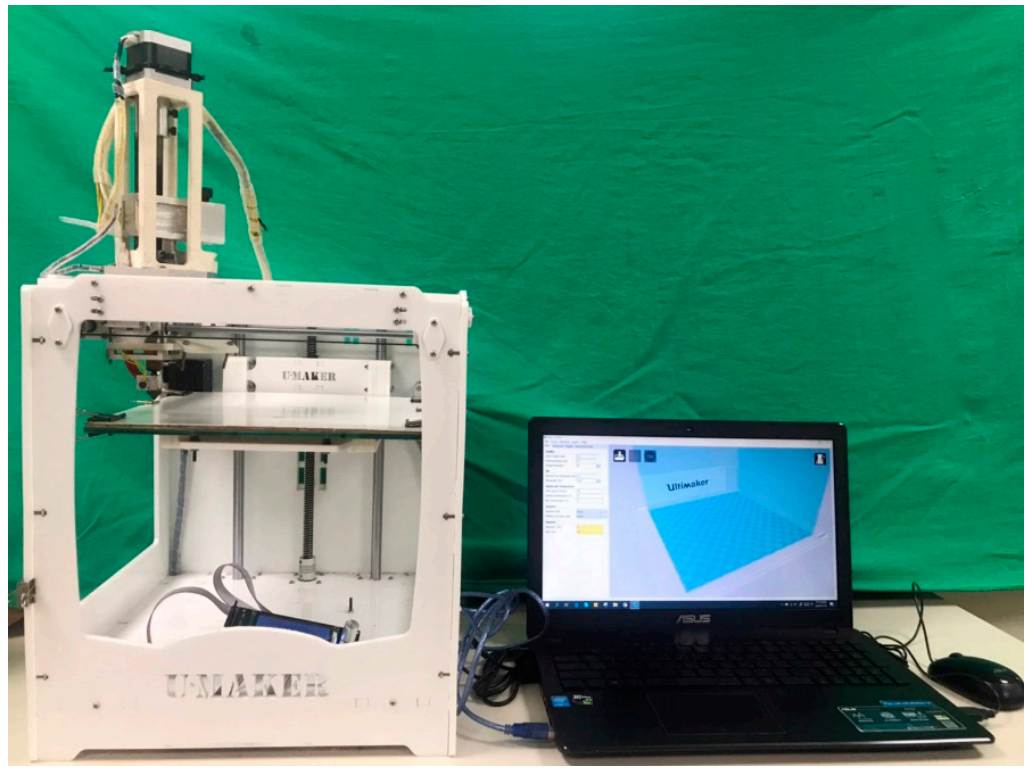

Figure 1. Photo of the solution extrusion additive manufacturing device, which consists of a solution-type plunger-actuated feeding system, stepper motors, motion components, a power supply unit, an accumulation platform, and a user interface with connectivity.

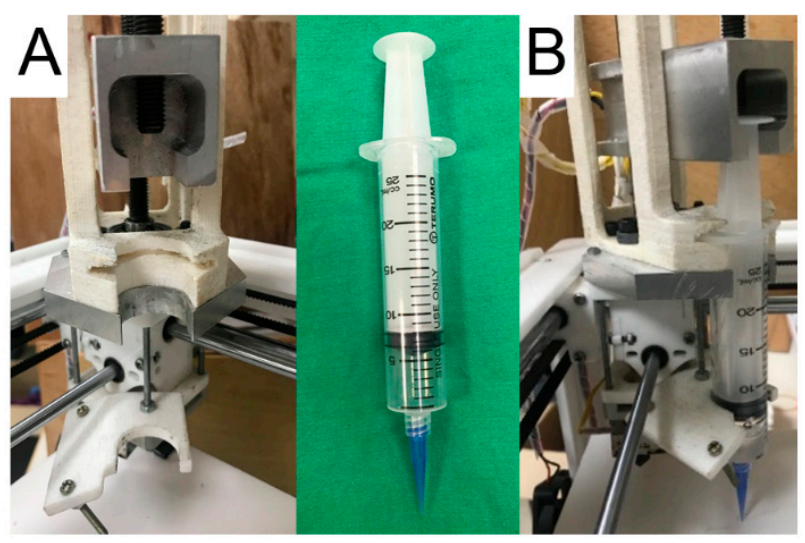

Figure 2. (A) Components of the dispensing unit in the solution extrusion additive manufacturing device, (B) assembly of the dispensing unit.

Figure 3 shows the entire extrusion manufacturing process. Predetermined weights of PCL pellets were first dissolved in DCM with various weight-to-volume ratios and mixed by a magnetic stirrer for $2 \mathrm{~h}$. The solution was subsequently poured into the feeding system, which has a syringe and a plastic dispensing tip for manufacturing. During additive manufacturing, the feeder is prompted by a microprocessor-controlled servo motor and expels the PCL solution onto the collection platform from the dispensing tip. Through the vaporization of solvent, PCL strips of approximately $0.2 \mathrm{~mm}$ in width are deposited on the platform layer-by-layer; each layer has a thickness of approximately $0.10-0.15 \mathrm{~mm}$. 
A

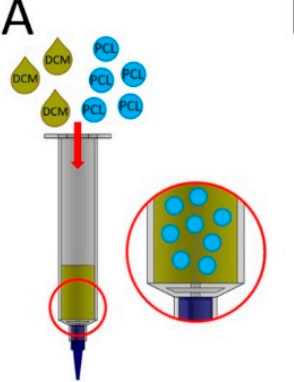

B

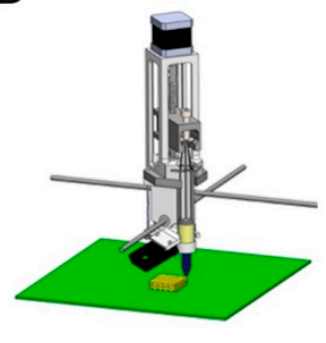

C

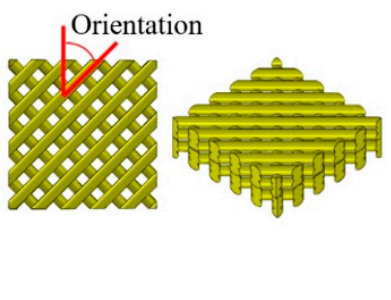

Figure 3. (A) Polycaprolactone (PCL) pellets were first mixed in dichloromethane (DCM), (B) the solution was poured into the syringe for additive manufacturing, (C) manufacturing of parts layer-by-layer with designated print orientation of infill.

\subsection{Empirical Parameters}

To estimate the influence of possible residual solvent on fabricated parts, a few specimens were first fabricated. The weights of the specimens were measured after placement in a ventilation chamber at room temperature $\left(25^{\circ} \mathrm{C}\right)$ for various periods of time (0-6 days). Five parameters were selected for the analysis: the PCL/DCM ratio, fill density, moving speed of the dispensing tip, and print orientation of infill of the extruded strips (Figure 3C). Before the experiments, a few test trials were first completed to determine the range of processing parameters that can successfully manufacture the parts. The processable range was then subdivided so as to examine the influence of each factor on the fabricated part's quality. The PCL/solvent (DCM) ratio $(w / v)$ was $5 \mathrm{~g} / 6.8 \mathrm{~mL}, 5 \mathrm{~g} / 7.0 \mathrm{~mL}, 5$ $\mathrm{g} / 7.1 \mathrm{~mL}$, or $5 \mathrm{~g} / 7.2 \mathrm{~mL}$. The fill density was $65 \%, 70 \%, 75 \%$, or $80 \%$. The moving speed of the dispensing tip ranged from 40 to $70 \mathrm{~mm} / \mathrm{s}$. The strips' print orientation of infill was set as $30^{\circ}, 45^{\circ}$, $75^{\circ}$, or $90^{\circ}$ (see Figure $3 \mathrm{C}$ ). Table 1 lists the parameters and parameter levels used in the experiments. The dispensing nozzle and the collection platform were not heated during the experimental procedure.

Table 1. Parameters used for the 3D printing experiments.

\begin{tabular}{ccccc}
\hline Factor & $\begin{array}{c}\text { A: PCL/DCM Ratio } \\
(\boldsymbol{w} / \boldsymbol{v})\end{array}$ & $\begin{array}{c}\text { B: Fill Density } \\
\mathbf{( \% )}\end{array}$ & $\begin{array}{c}\text { C: Print Speed } \\
(\mathbf{m m} / \mathbf{s})\end{array}$ & $\begin{array}{c}\text { D: Print Orientation } \\
\text { of Infill }\end{array}$ \\
\hline Level 1 & $5 \mathrm{~g} / 6.8 \mathrm{~mL}$ & 65 & 40 & $30^{\circ}$ \\
Level 2 & $5 \mathrm{~g} / 7 \mathrm{~mL}$ & $\mathbf{7 0}$ & 50 & $45^{\circ}$ \\
Level 3 & $5 \mathrm{~g} / 7.1 \mathrm{~mL}$ & 75 & 60 & $75^{\circ}$ \\
Level 4 & $5 \mathrm{~g} / 7.2 \mathrm{~mL}$ & 80 & 70 & $90^{\circ}$ \\
\hline
\end{tabular}

A geometry for tensile tests (Figure 4A) was used to manufacture the part samples. A commercially available computer-aided design software (Solidworks, Waltham, MA, USA) was employed to produce the code for controlling the movement of the dispensing tip. After additive manufacturing, the mechanical properties of the manufactured dumbbell-shaped parts were evaluated using a tensile tester (Lloyd, Ameteck, Berwyn, PA, USA) with a $2500 \mathrm{~N}$ load cell by following the ASTM D638 standard. The tensile pulling speed was set as $60 \mathrm{~mm} / \mathrm{min}$. The tensile strength was computed as follows:

Tensile strength $(\mathrm{MPa})=$ Breaking force $(\mathrm{N}) /$ Cross-sectional area of sample $\left(\mathrm{mm}^{2}\right)$ 

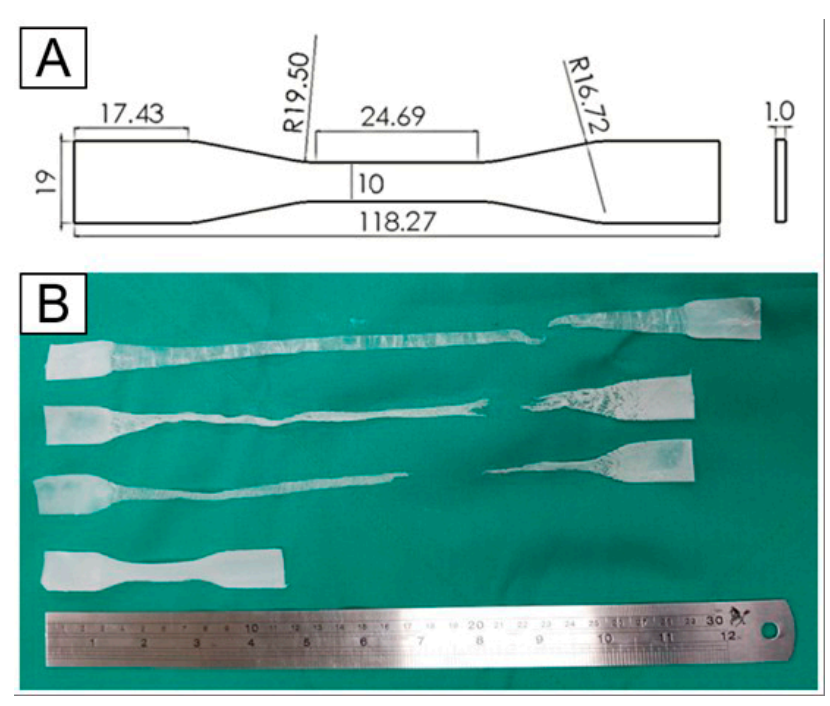

Figure 4. (A) Layout and dimensions of the tensile test, (B) photo of specimens before and after the tensile tests.

A full factorial experiment allows the investigator to investigate the effect of each factor on the response variable, as well as the effects of interactions between factors on the response variable. However, it requires a large number of samples and experimental trials, which is time-consuming. A single-factor experimental design utilizes experimental methodology to focus on only one subject. This design is distinct from case study methodology, which also focuses on one individual, because single-factor experimental designs use the same systematic processes as other experimental designs. The investigator establishes the study to manipulate an independent variable (or variables) and to measure how a dependent variable responds to changes in the independent variable. This design has the experimental benefit of a controlled comparison, because the individual subject serves as the control by engaging in all of the conditions [14]. In this study, the single-factor experimental design was employed, where a set of arbitrarily selected processing condition (Level 2 in Table 1) was selected as a reference. By altering one of the parameters each time while keeping the others unchanged, we were able to study the influence of every parameter on the mechanical properties of the parts. Five sample tests were completed for each trial.

\subsection{Microscopic Observations}

The morphology of the additively manufactured parts was observed under a profile projector (APEX-2010, Taipei, Taiwan) and a field emission scanning electron microscope (FESEM) (JEOL Model JSM-7500F, Tokyo, Japan).

\subsection{Thermal Analysis}

A differential scanning calorimeter (Model DSC25, TA Instruments, New Castle, DE, USA) was used to characterize the thermal properties of the PCL pellets and the additively manufactured PCL specimens. The scan temperature was between 30 and $90^{\circ} \mathrm{C}$, and the heating speed of the samples was set as $10^{\circ} \mathrm{C} / \mathrm{min}$. For comparison, the thermal profiles of the parts were also characterized after annealing them in an oven at $50^{\circ} \mathrm{C}$ for $1 \mathrm{~h}$.

\section{Results}

PCL parts were successfully fabricated using the solution extrusion additive manufacturing device. The measured parts' weight and length variations at $0-6$ days post-manufacturing are shown in Table 2. The weight and size decreased, which predominately resulted from the evaporation of the remaining solvents in the fabricated samples. The weight decrease and sample shrinkage became 
stable at 2 days post-manufacture, and the final weight and size decreased by about $4.23 \%$ and $13.8 \%$, respectively. Other than the dimensional shrinkage, no warpage or distortion of manufactured parts was observed (see the sample before the tensile test in Figure 4B).

Table 2. Weight and size variations of manufactured parts with time.

\begin{tabular}{cccccccc}
\hline Day & $\mathbf{0}$ & $\mathbf{1}$ & $\mathbf{2}$ & $\mathbf{3}$ & $\mathbf{4}$ & $\mathbf{5}$ & $\mathbf{6}$ \\
\hline Weight, grams & 3.008 & 2.594 & 2.592 & 2.592 & 2.592 & 2.592 & 2.592 \\
(reduction, \%) & $(0 \%)$ & $(13.7 \%)$ & $(13.8 \%)$ & $(13.8 \%)$ & $(13.8 \%)$ & $(13.8 \%)$ & $(13.8 \%)$ \\
\hline Length, cm & 11.8 & 11.3 & 11.3 & 11.3 & 11.3 & 11.3 & 11.3 \\
$($ shrinkage, $\%)$ & $(0 \%)$ & $(4.23 \%)$ & $(4.23 \%)$ & $(4.23 \%)$ & $(4.23 \%)$ & $(4.23 \%)$ & $(4.23 \%)$ \\
\hline
\end{tabular}

Figure 4B shows the fractured parts before and after the tensile test. All parts showed good ductile characteristics. Figures 5-8 show the tensile properties of parts manufactured using different processing conditions, and Figures 9-12 show surface images from the profile projector and SEM.
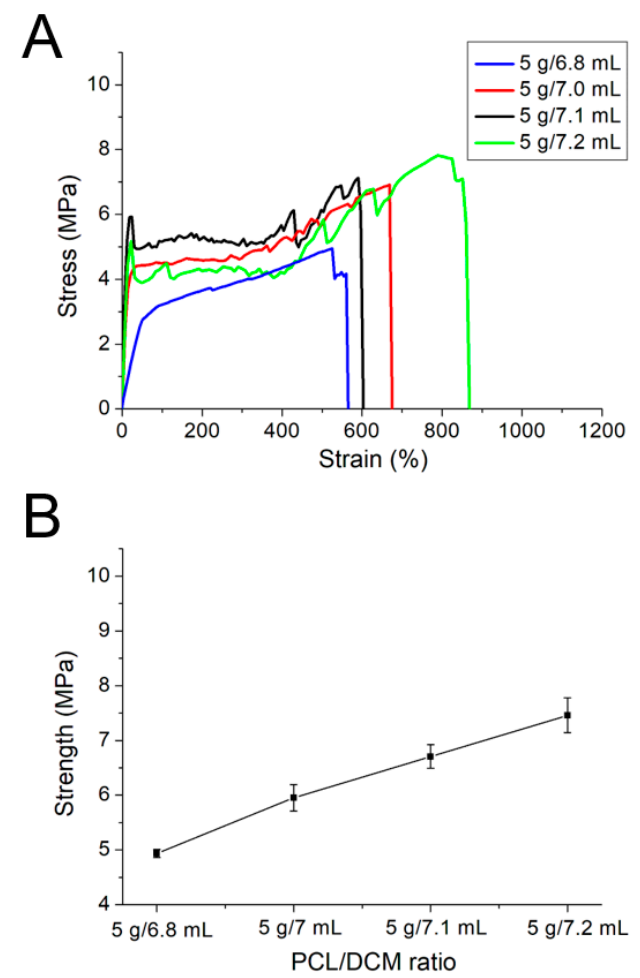

Figure 5. Effect of the PCL/DCM ratio on the mechanical properties of additively manufactured PCL parts ((A): stress strain curves; (B): maximum tensile strengths, other parameters used were those of Level 2 in Table 1). 

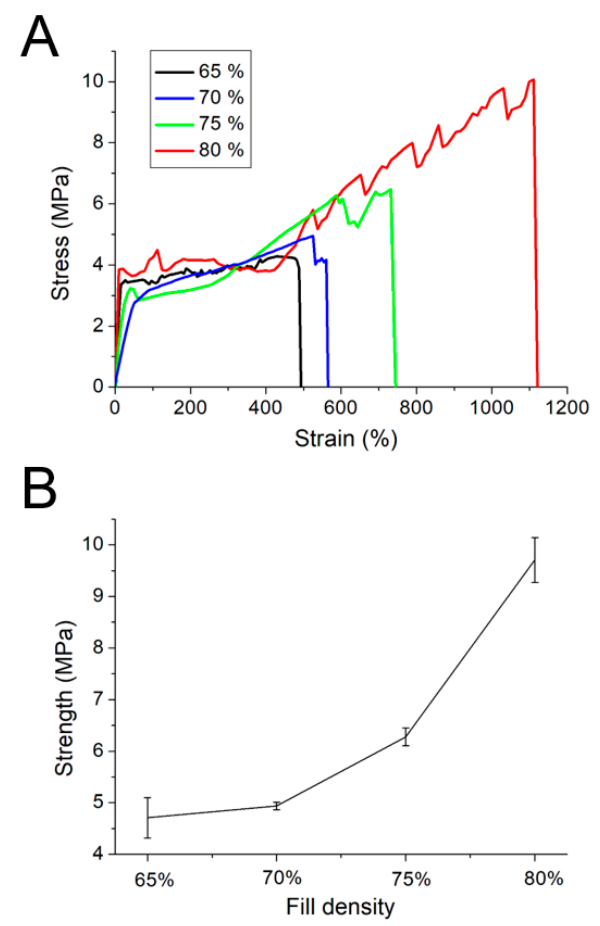

Figure 6. Effect of fill density on the mechanical properties of additively manufactured PCL parts ((A): stress strain curves; (B): maximum tensile strengths, other parameters used were those of Level 2 in Table 1).
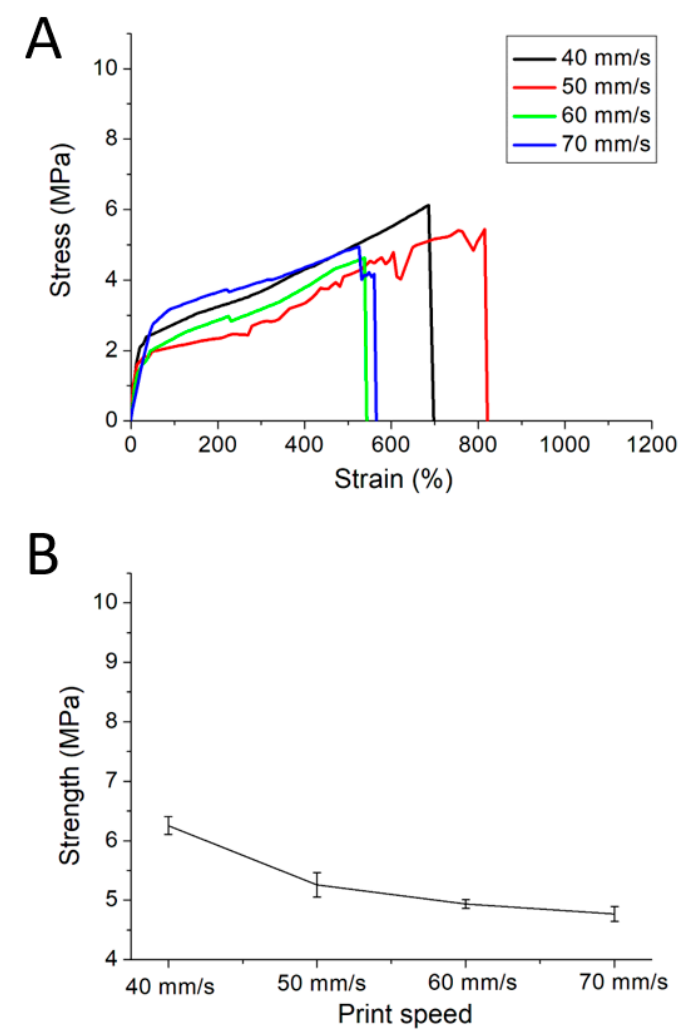

Figure 7. Effect of print speed on the mechanical properties of additively manufactured PCL parts ((A): stress strain curves; (B): maximum tensile strengths, other parameters used were those of Level 2 in Table 1). 

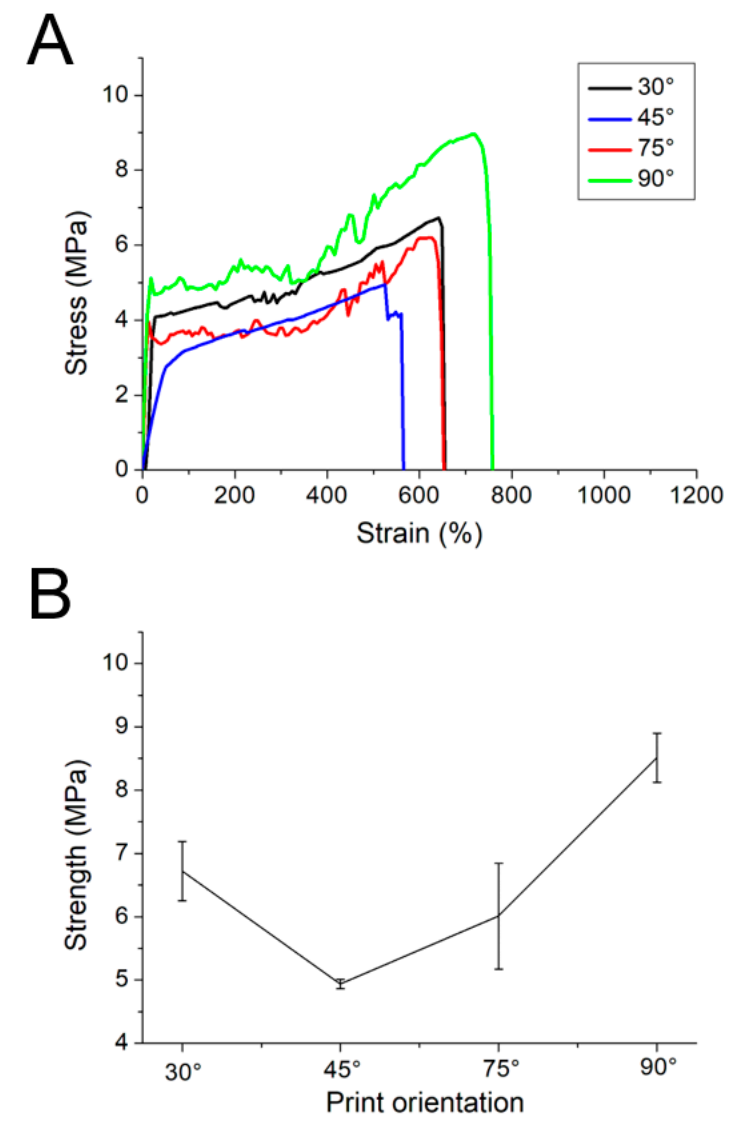

Figure 8. Effect of print orientation of infill on the mechanical properties of additively manufactured PCL parts ((A): stress strain curves; (B): maximum tensile strengths, other parameters used were those of Level 2 in Table 1).

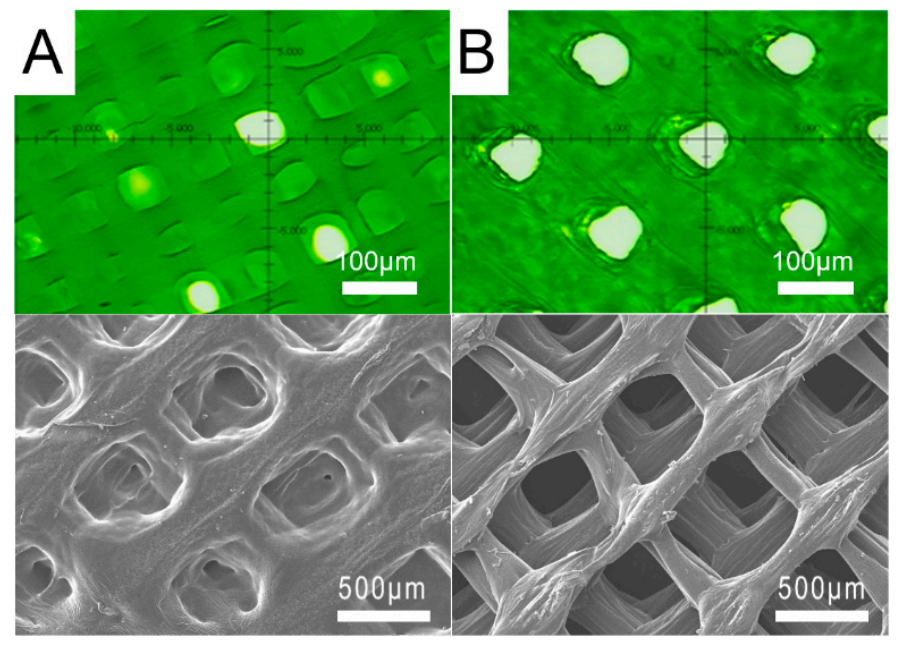

Figure 9. Profile projector and FESEM images of parts manufactured with PCL/DCM ratios of (A) $5 \mathrm{~g} / 7.2 \mathrm{~mL}$, (B) $5 \mathrm{~g} / 6.8 \mathrm{~mL}$. 


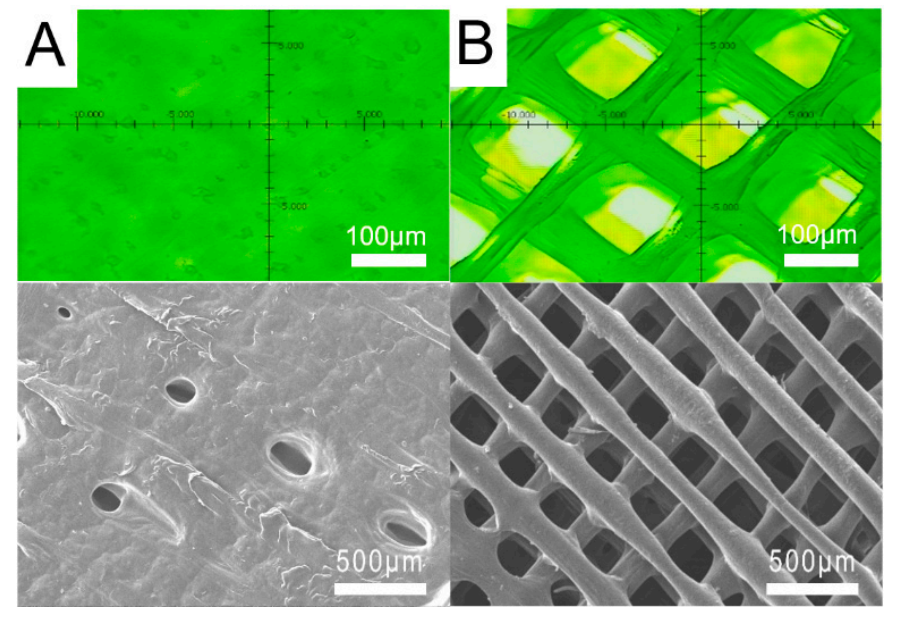

Figure 10. Profile projector and FESEM images of parts fabricated with fill densities of (A) $80 \%$, (B) $65 \%$.

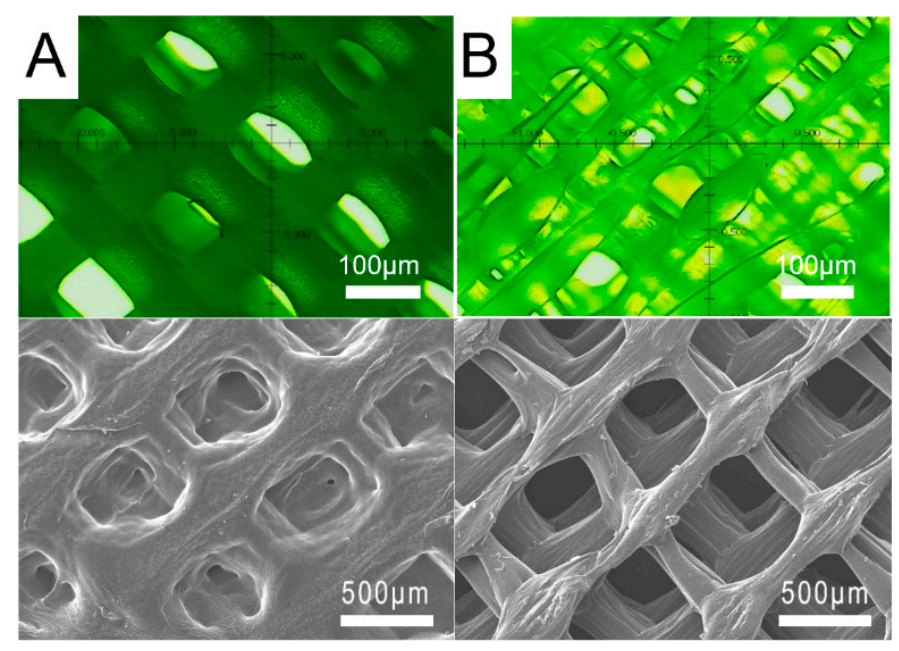

Figure 11. Profile projector and FESEM images of parts manufactured with tip speeds of (A) $40 \mathrm{~mm} / \mathrm{s}$, (B) $70 \mathrm{~mm} / \mathrm{s}$.

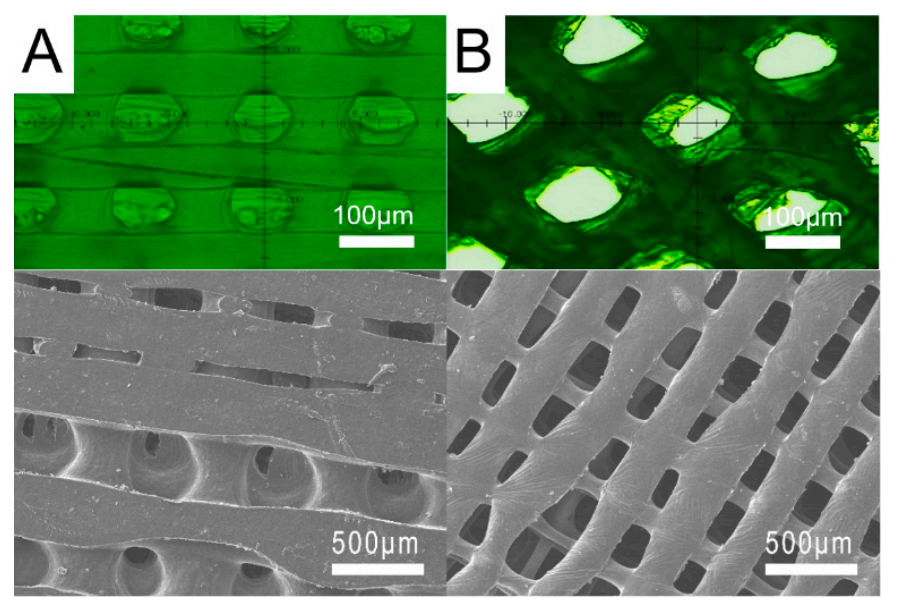

Figure 12. Profile projector and FESEM images of parts manufactured with orientations of (A) $90^{\circ}$, (B) $45^{\circ}$. 


\subsection{Effects of Processing Parameters on Part Strength}

Figure 5A shows the stress-strain curves of parts prepared using different PCL/DCM ratios, while Figure 5B shows the maximum tensile strengths. The elongation at break generally increased with the volume of DCM. The maximum tensile strengths also increased as the volume of DCM increased. Parts manufactured using a ratio of $5 \mathrm{~g} / 7.2 \mathrm{~mL}$ exhibited the greatest tensile strength, while fabricated parts with a ratio of $5 \mathrm{~g} / 6.8 \mathrm{~mL}$ showed the worst mechanical properties.

Figure 9 shows the surface images of manufactured parts. Incompletely sealed orifices can be seen on surfaces of the solution extrusion manufactured products in the profile projector image. Small orifices were observed on the part surface, which mainly resulted from the evaporation of solvent. Better healing is observed in Figure 9A $(5 \mathrm{~g} / 7.2 \mathrm{~mL})$ than in Figure $9 \mathrm{~B}(5 \mathrm{~g} / 6.8 \mathrm{~mL})$, not only in the same layer but also across layers. Since the part made with the $5 \mathrm{~g} / 6.8 \mathrm{~mL}$ solution showed greater pore sizes than parts made with $5 \mathrm{~g} / 7.2 \mathrm{~mL}$, it shows worse mechanical properties.

Figure 6A shows the stress-strain curves of parts manufactured using different fill densities. Clearly, the maximum strength and elongation at break increased with the fill density. Figure $6 \mathrm{~B}$ shows the influence of fill density on the maximum tensile strength of the fabricated parts. Parts with $80 \%$ fill density exhibited the greatest tensile strength, while parts fabricated with $65 \%$ exhibited the lowest mechanical properties.

Figure 10A,B show the surface images of parts manufactured with $80 \%$ and $65 \%$ fill density, respectively. The surface of parts manufactured with $80 \%$ fill density are almost completely healed, but huge pores could still be seen on the surface of parts prepared with $65 \%$ fill density. Parts manufactured with a lower fill density showed larger pores, which may lead to stress concentrations during the tensile tests. Thus, they demonstrated lower mechanical strength.

Figure 7A shows the tensile test curves of parts manufactured with various speeds of the dispensing tip. Figure 7B shows the effect of the tip's moving speed on the maximum tensile strength. The tensile strength decreased generally with the tip's speed. Parts prepared using a speed of $40 \mathrm{~mm} / \mathrm{s}$ exhibited the greatest tensile strength, while parts fabricated with a speed of $70 \mathrm{~mm} / \mathrm{s}$ showed the lowest mechanical properties.

Figure 11A,B show the surface images of parts manufactured using tip speeds of $40 \mathrm{~mm} / \mathrm{s}$ and $70 \mathrm{~mm} / \mathrm{s}$, respectively. Again, all parts exhibit a fused surface with many incompletely healed small pores. Furthermore, parts manufactured with a tip speed of $70 \mathrm{~mm} / \mathrm{s}$ showed pores of greater size than those fabricated with a tip speed of $40 \mathrm{~mm} / \mathrm{s}$. Thus, they showed worse mechanical properties.

Figure $8 \mathrm{~A}$ shows the stress-strain curves of parts manufactured using different orientations of $30^{\circ}$, $45^{\circ}, 75^{\circ}$, and $90^{\circ}$, and Figure $8 \mathrm{~B}$ shows the maximum tensile strength of these samples. The specimen manufactured with an orientation of $90^{\circ}$ showed the greatest tensile strength, while $45^{\circ}$ resulted in the lowest mechanical properties. Figure 12 shows the surface images of the parts manufactured with orientations of $90^{\circ}$ and $45^{\circ}$. Obviously, $45^{\circ}$ resulted in more large pores on the surface. Furthermore, compared to $90^{\circ}, 45^{\circ}$ resulted in sharp rectangular pores. Meanwhile, due to the different print orientation of infill, the interlayer fusion of PCL strips might be different, which in turn leads to various bonding intensities and relevant mechanical strengths. This might explain why the strength of the $30^{\circ}$ manufactured part is higher than that of the $45^{\circ}$.

When these pores are subjected to external forces, stress concentrations may occur and lead to fractures. The strength decreased accordingly. We were able to successfully manufacture 2D and 3D products of various geometries by using the optimum processing conditions of a PCL/DCM ratio of $5 \mathrm{~g} / 7.2 \mathrm{~mL}$, a fill density of $80 \%$, a tip moving speed of $40 \mathrm{~mm} / \mathrm{s}$, and a print orientation of $90^{\circ}$, as shown in Figure 13. 


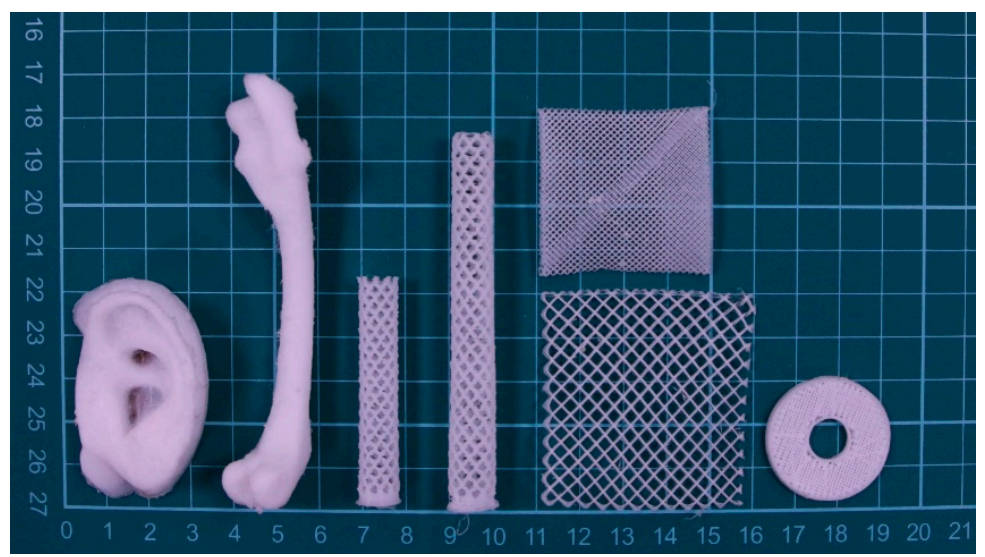

Figure 13. Various PCL parts additively manufactured using the optimum processing conditions.

\subsection{Influence of Solvent}

Figure 14 shows the DSC curves of the virgin PCL materials, the solution extrusion manufactured PCL, and the manufactured PCL parts after being annealed in an oven at $50^{\circ} \mathrm{C}$ for $1 \mathrm{~h}$. The virgin PCL exhibited a crystallization exotherm near $60^{\circ} \mathrm{C}$. After the addition of solvent, the solution fabricated PCL became an amorphous state and showed no obvious crystallization exotherm or melting temperature on the DSC curve. After the annealing process, the annealed parts regained the crystallization exotherm, and the melting temperature decreased to around $42{ }^{\circ} \mathrm{C}$.

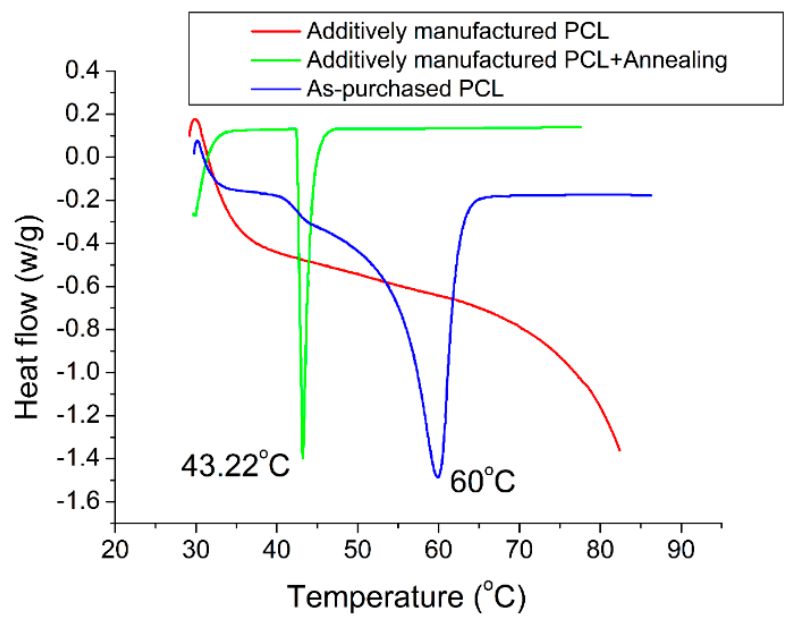

Figure 14. DSC curves of PCL: as purchased, after solution extrusion additive manufacturing, and after solution extrusion manufacturing and annealing.

\section{Discussion}

Two factors might affect the mechanical properties of an additively manufactured product and determine the success of the product in a given application. The first factor is the healing or fusion of layer interfaces, and the second is the size of the pores. To produce parts of greater strength in solution extrusion additive manufacturing, the enhancement of chain entanglements [15] at the strip interface is essential and is responsible for the final mechanical properties of additively manufactured products [16].

In solution extrusion, solvent exhalation and diffusion of molecular chains occur at the solidification stage of polymeric materials. It has been reported that in the solution processing of polymers, the optimum solution is a semi-dilute, mildly entangled pattern, which occurs at the critical entanglement concentration Ce [17] (10-12 w/v\% for PCL when DCM is used as the solvent [18]). 
This period is a critical point between a semi-dilute unentangled pattern and a semi-dilute mildly entangled pattern. In this range, enhanced healing at the strip interfaces can be anticipated. Despite the PCL concentration used (approximately 7\%) in this work being less than optimal, fusion and healing at the interface was still expected. As for the second factor, a solution extrusion additively manufactured part may have tiny incompletely fused pores and cracks, which may lead to stress concentrations when subjected to external forces. The strength of fabricated parts is thus decreased.

The experimental results in Figure 5 suggest that the strength of the manufactured parts increased with the volume of DCM. The parts made with PCL/DCM $=5 \mathrm{~g} / 7.2 \mathrm{~mL}$ had the highest mechanical strength. When less solvent was used, the solvent can volatilize too rapidly, leading to insufficient time for the polymeric solution to go through molecular entanglement at the strip interfaces. A higher concentration of DCM maintains the polymeric materials in a semi-dilute state for a sustained period of time and helps the polymeric strips to fuse and close up at the interfaces. This occurs not only in the same layer but also across various layers, as shown in Figure 9. Thus, the parts exhibited higher strength.

The data in Figure 6 suggest that the mechanical properties of the parts increased with the fill density. The fill density is defined as the amount of polymer used in fabricating a specimen. A higher fill density implies more plastic material within the manufactured samples, thus resulting in a stronger product. Furthermore, filling the parts with more material also leads to smaller pore sizes (Figure 10), which increases the manufactured part's quality. Meanwhile, as pointed out earlier, the strength of the manufactured parts also increased with the volume of DCM. Therefore, there exists a balance between volume of DCM and amount of polymer that leads to the maximum strength.

The empirical data in Figure 7 suggest that the strength decreases with the print speed. Once the solution is expelled from the dispensing tip, the solvent starts to volatilize. When the tip is too fast, not as much time is allowed for the solution to go through molecular entanglement at the strip's interface (Figure 11). In addition, the solvent may not have enough time to evaporate. The excessive solvent may spread and dissolve the neighboring strips and decrease the chain entanglement. The strength decreased accordingly.

The parts fabricated with a $45^{\circ}$ print orientation of infill exhibited the lowest strength, while $90^{\circ}$ resulted in the greatest part strength. One possible explanation is that the $90^{\circ}$ orientation of extruded strips limits the amount of solvent that quickly evaporates. There is sufficient time for the polymeric liquid to experience molecular entanglement at the interfaces (Figure 12A). The mechanical strength of specimens increased accordingly. An orientation of $45^{\circ}$ resulted in diamond-shape pores (Figure 12B). When subjected to external tensile forces, these diamond-shaped pores may experience stress concentrations at the corners. The fabricated products thus exhibited the worst tensile properties.

Finally, the polymer crystallization may be changed by placing the material in an environment with organic solvents $[19,20]$. In the presence of DCM, PCL materials turned into an amorphous state [21]. Despite their lowest crystallinity, the experimental data demonstrated that the solution manufactured PCL parts exhibited excellent ductility (Figure 4B). Furthermore, the annealing helps to regain the crystallinity of the polymeric materials [22]. All these results demonstrated the feasibility of the solution extrusion additive manufacturing technique for PCL materials.

\section{Conclusions}

This study investigated the solution extrusion additive manufacturing of PCL using a lab-developed device. The effects of various parameters on the fabricated parts' quality were investigated. The experimental results suggest that the tensile strength of the produced parts increases with the fill density but decreases with the PCL/DCM ratio and the dispensing tip's moving speed. Parts manufactured with a $90^{\circ}$ print orientation of infill exhibited the greatest mechanical strength. After fabrication, the parts' gaps among the strips tended to heal. However, tiny pores could still be seen on the surfaces. 
Author Contributions: Conceptualization, J.-M.C. and D.L.; methodology, J.-W.Y.; formal analysis, J.-M.C. and S.-H.L.; investigation, D.L., S.-H.L., and Y.-T.L.; data curation, J.-M.C. and D.L.; writing-original draft preparation, S.-J.L.; writing-review and editing; funding acquisition, S.-J.L. All authors have read and agreed to the published version of the manuscript.

Funding: This research was funded by the Ministry of Science and Technology, Taiwan (Contract No. 108-2221-E-182-004), and Chang Gung Memorial Hospital (Contract No. CMRPD2K0081).

Conflicts of Interest: The authors declare no conflict of interest.

\section{References}

1. Woodruff, M.A.; Hutmacher, D.W. The return of a forgotten polymer-Polycaprolactone in the 21st century. Prog. Polym. Sci. 2010, 35, 1217-1256. [CrossRef]

2. Labeta, M.; Thielemans, W. Synthesis of polycaprolactone: A review. Chem. Soc. Rev. 2009, 38, 3484-3504. [CrossRef] [PubMed]

3. Dwivedi, R.; Kumar, S.; Pandey, R.; Mahajan, A.; Nandana, D.; Katti, D.S.; Mehrotra, D. Polycaprolactone as biomaterial for bone scaffolds: Review of literature. J. Oral Biol. Craniofac. Res. 2020, 10, 381-388. [CrossRef] [PubMed]

4. Ngo, T.D.; Kashani, A.; Imbalzano, G.; Nguyen, K.T.Q.; Hui, D. Additive manufacturing (3D printing): A review of materials, methods, applications and challenges. Compos. Part B 2018, 143, 172-196. [CrossRef]

5. Bekas, D.G.; Hou, Y.; Liu, Y.; Panesar, A. 3D printing to enable multifunctionality in polymer-based composites: A review. Compos. Part B 2019, 179, 107540. [CrossRef]

6. Beheshtizadeh, N.; Lotfibakhshaiesh, N.; Pazhouhnia, Z.; Hoseinpour, M.; Nafari, M. A review of 3D bio-printing for bone and skin tissue engineering: A commercial approach. J. Mater. Sci. 2019, 55, 3729-3749. [CrossRef]

7. Egan, P.F. Integrated design approaches for 3D printed tissue scaffolds: Review and outlook. Materials 2019, 12, 2355. [CrossRef]

8. Alafaghani, A.; Qattawi, A.; Alrawi, B.; Guzman, A. Experimental optimization of Fused Deposition Modelling processing parameters: A design-for-manufacturing approach. Procedia Manuf. 2017, 10, 791-803. [CrossRef]

9. Guerra, A.J.; Ciurana, J. 3D-printed bioabsordable polycaprolactone stent: The effect of process parameters on its physical features. Mater. Des. 2018, 137, 430-437. [CrossRef]

10. Jiao, Z.; Luo, B.; Xiang, S.; Ma, H.; Yu, Y.; Yang, W. 3D printing of HA/PCL composite tissue engineering scaffolds. Adv. Ind. Eng. Polym. Res. 2019, 2, 196-202. [CrossRef]

11. Holländer, J.; Genina, N.; Jukarainen, H.; Khajeheian, M.; Rosling, A.; Makila, E.; Sandler, N. Three-dimensional printed PCL-based implantable prototypes of medical devices for controlled drug delivery. J. Pharm. Sci. 2016, 105, 2665-2676. [CrossRef] [PubMed]

12. Visscher, L.E.; Dang, H.P.; Knackstedt, M.A.; Hutmacher, D.W.; Tran, P.A. 3D printed Polycaprolactone scaffolds with dual macro-microporosity for applications in local delivery of antibiotics. Mater. Sci. Eng. C 2018, 87, 78-89. [CrossRef] [PubMed]

13. Yi, H.G.; Choi, Y.J.; Kang, K.S.; Hong, J.M.; Pati, R.G.; Park, M.N.; Shim, I.K.; Lee, C.M.; Kim, S.C.; Cho, D.W. A 3D-printed local drug delivery patch for pancreatic cancer growth suppression. J. Contr. Release 2016, 238, 231-241. [CrossRef] [PubMed]

14. Selvamuthu, D.; Das, D. Single-Factor Experimental Design. In Introduction to Statistical Methods, Design of Experiments and Statistical Quality Control; Springer: Singapore, 2018.

15. Yokomizo, K.; Banno, Y.; Yoshikawa, T.; Kotaki, M. Effect of molecular weight and molecular weight distribution on weld-line interface in injection-molded polypropylene. Polym. Eng. Sci. 2013, 53, 2336-2344. [CrossRef]

16. Yizong, T.; Ariff, Z.M.; Liang, K.G. Evaluation of weld line strength in low density polyethylene specimens by optical microscopy and simulation. J. Eng. Sci. 2017, 13, 53-62.

17. Cipitria, A.; Skelton, A.; Dargaville, T.R.; Dalton, P.D.; Hutmacher, D.W. Design, fabrication and characterization of PCL electrospun scaffolds-A review. J. Mater. Chem. 2011, 21, 9419-9453. [CrossRef] 
18. Costa, L.M.M.; Bretas, R.E.S.; Gergorio, R., Jr. Effect of solution concentration on the electrospray/electrospinning transition and on the crystalline phase of PVDF. Mater. Sci. Appl. 2010, 1, 247-252. [CrossRef]

19. Kong, Y.; Ma, Y.; Lei, L.; Wang, X.; Wang, H. Crystallization of poly(e-caprolactone) in poly(vinylidene fluoride)/poly(E-caprolactone) blend. Polymers 2017, 9, 42. [CrossRef]

20. Andjelic, S.; Scogna, R.C. Polymer crystallization rate challenges: The art of chemistry and processing. J. Appl. Polym. Sci. 2015, 132, 42066. [CrossRef]

21. Chen, J.M.; Tseng, Y.Y.; Lee, D.; Lin, Y.T.; Lin, S.H.; Lee, T.Y.; Liu, S.J.; Ito, H. A robust experimental model to explore the three-dimensional printing of polylactide parts: Solution vs. melt extrusion. Appl. Sci. 2020, 10, 509. [CrossRef]

22. Vadas, D.; Nagy, Z.K.; Csontos, I.; Marosi, G.; Bocz, K. Effects of thermal annealing and solvent-induced crystallization on the structure and properties of poly (lactic acid) microfibres produced by high-speed electrospinning. J. Therm. Anal. Calorim. 2020. [CrossRef]

(C) 2020 by the authors. Licensee MDPI, Basel, Switzerland. This article is an open access article distributed under the terms and conditions of the Creative Commons Attribution (CC BY) license (http://creativecommons.org/licenses/by/4.0/). 